\title{
Statistical Interrelationships of Job Competition between Generations
}

\author{
Tae Ho Kim ${ }^{1}$. Jae Hwa Jung ${ }^{2}$ \\ ${ }^{1}$ Department of Information Statistics, Chungbuk National University \\ ${ }^{2}$ Department of Information Statistics, Chungbuk National University \\ (Received April 9, 2012; Revised April 20, 2012; Accepted May 9, 2012)
}

\begin{abstract}
Job competition among generations has become an important social issue that has yet to be studied from an academic viewpoint. This study performs statistical tests to investigate the interrelation of employment among generations using seasonally adjusted monthly time series data. Employment by generations is not found to be strongly interrelated, even if the employment of 30-year-olds appears to affect those of 40-yearolds in some tests.
\end{abstract}

Keywords: Employment rate, lead-lag relationship, final prediction error.

\section{1. 서론}

실업률은 고용동향을 나타내는 중요한 통계지표이지만 국내 노동시장 상황을 판단하거나 고용정책의 기 준을 대변하기에는 현실과 괴리되어 있다는 비판이 꾸준히 제기되어 왔다. 실업률 수준이 지나치게 과 소측정되어 $\mathrm{OECD}$ 국가들 가운데 최저에 해당하면서도 국내 고용률 또한 최저 수준에 속한다는 것이다. 실업률 통계는 경제활동 참가 여부가 변하는 한계적 경제활동참가자에 의해 영향을 받게 되는 문제가 있 다. 낮은 실업률이 높은 비율의 비경제활동인구에 의한 것이며, 공식적인 실업에는 포함되지 않는 잠재 적 실업자들이 광범위하게 존재한다. Kang 등 (1999)는 공식실업률이 포착하지 못하는 잠재실업자를 고려하기 위해 보완적 지표의 필요성에 대해 연구하였으며, Hwang (2010)은 국내 실업률이 현실 고용 사정을 대변하지 못하는 결함을 보완하기 위해 잠재실업 및 불완전취업을 포괄하는 확장실업지표를 제 안하였다. 선행연구들은 실업률이 노동시장의 상황을 바르게 측정했다는 가정 하에 사용해 왔으나 실업 률은 실제의 실업사정을 과소평가하게 되어 분석에 오류를 가져오게 된다. Kim와 Chang (2005)는 지 표로서 실업률의 한계를 지적하고 고용률의 유용성을 강조하였으며, $\mathrm{OECD}$ 와 $\mathrm{EU}$ 집행위원회도 고용 률에 더 관심을 보이고 이의 사용을 적극 권장해 왔다.

최근 인구고령화로 고용구조가 중·고령층 위주로 재편되면서 세대 간 일자리 경합문제가 발생하게 되었 다. 세대 간 고용대체 현상이 발생하는 요인은 경기회복이 지연되면서 일자리 나누기에 따른 기존 인 력 유지로 기업의 채용규모가 감소하고, 경력자 위주의 수시채용이 확산되어 청년층의 신규채용 여력을 감소시키기 때문으로 사료된다. 세대 간 일자리 경합과 관련해 $\operatorname{Kim}(2008)$ 는 국내 실업을 청년실업과

\footnotetext{
${ }^{1}$ Corresponding author: Professor, Department of Information Statistics, Chungbuk National University, 410 Seongbong-Ro, Heungduk-Gu, Cheongju, Chungbuk 361-763, Korea. E-mail: thkim@chungbuk.ac.kr
} 
Table 1.1. Correlation coincidence index-unemployment and employment rates

\begin{tabular}{ccc}
\hline & 실업률 & 고용률 \\
\hline 상관계수 & -0.2300 & 0.5030 \\
유의확률(양쪽) & $(0.1240)$ & $(0.0000)$ \\
\hline
\end{tabular}

중년실업으로 구분하여 동태방정식 통계모형체계를 이용, 이들의 단기적 변동구조와 장기적 적응과정을 추정하고 비교, 분석하였다. Kwan (2010)는 청년층과 고령층의 일자리 선호 영역이 다르므로 세대 간 경합 가능성은 낮다는 연구결과를 제시했으나 Card와 Lemieux (2001)는 이들 간 대체성을 주장한 바 있다. 산업수요와 대학교육 간 미스매치, 또 고학력과 임금수준 간 미스매치로 인해 청년층의 적절한 일 자리 취업이 확대되지 못했으며 2000 년대 중반 이후 청년층 고용률 하락은 일자리 창출력 저하에 따른 세대 간 경합의 결과로 간주되기도 한다. Chun과 Lee (2010)는 대졸자의 노동시장 진입 후 구직 및 이 직 등을 통한 일자리 경험 횟수분포를 유도하였다. 외환위기 이후 20 대와 50 대 고용률이 모두 그전 수 준을 회복하지 못했으나 글로벌 금융위기 이후 50 대는 바로 이전 수준을 회복했지만 20 대는 하락세를 되돌리지 못했다 (Sung, 2011). 2006년 이후 20대 취업자가 매년 감소하는 데 반해 50대 취업자 수는 급증세를 타고 있다. 50 대 고용률의 증가 요인은 베이비붐 세대가 이 연령대에 진입하면서 50 대의 노동 력 비중이 크게 증가, 노동력의 연령별 구성이 크게 변화하기 시작하고 50 대 여성의 노동시장 진출이 활 발해졌기 때문으로 해석된다.

세대 간 일자리 경합문제는 사회적 이슈임에도 불구하고 이에 대한 학문적 분석은 거의 이루어지지 않 고 있다. 본 연구에서는 노동시장의 전반적 동향을 나타내는 통계지표로 실업률 대신 고용률을 사용하 여 현 정부 집권 후 연령대별 고용 간에 어떠한 연관관계가 존재하는지 통계적 검정을 실시하여 전반적 상황을 파악하고자 한다. 경기와 실업률 또 고용률과의 상관관계를 보면 현재의 경기동향인 경기동행지 수 순환변동치와 고용률 간 상관계수가 통계적으로 유의하며, Table 1.1에 요약된 바와 같이 실업률 자 료보다는 고용률 자료가 현실을 더 잘 반영하는 것으로 나타난다.

\section{2. 변수 검정}

Lee 등 (2011)는 인구고령화의 경제적 파장에 대한 연구에서 50 대와 20 대 일자리 간에 대체관계가 존재 하는지 20 대 고용률을 종속변수로, 또 50 대 고용률과 경기지수를 독립변수로 한 회귀모형을 2000 년대 전체와 2000 년대 후반기의 두 기간에 대해 추정하였다. 2000 년 대 전체로는 50 대와 20 대의 고용변동이 무관했으나 2005년 이후 50 대의 고용 증가가 20 대의 고용 감소에 유의한 영향을 미쳐 세대 간 고용대 체가 발생한 것으로 추정되었으며, 글로벌 금융위기 이후 경합이 다소 완화된 것으로 나타났다. 본 연구 에서는 20 대 $\left(L_{2}\right), 30$ 대 $\left(L_{3}\right), 40$ 대 $\left(L_{4}\right), 50$ 대 $\left(L_{5}\right)$ 고용률의 계절조정 자료를 사용하며 연구기간 동안의 월 추이는 Figure 2.1 과 같다.

각 변수들의 기초통계량은 Table 2.1과 같이 요약된다. 자료의 정규성에 대한 Jarque-Bera 검정 결과 시계열이 정규분포를 한다는 귀무가설은 유의수준 $10 \%$ 에서 기각되지 못한다. 왜도가 40 대 고용률을 제 외하고는 0 보다 커 우측 꼬리가 긴 분포를 하고, 첨도는 50 대 고용률 외는 모두 3 보다 작으므로 정규분 포보다 완만한(Platykurtic)분포를 따르는 것으로 나타난다.

실제의 경제시계열은 대부분 시간이 흐름에 따라 평균과 분산이 변화하는 비정상성을 가지며 대부분이 차분안정적인 것으로 알려져 있다. 따라서 자료의 정상성 검정을 먼저 실시하며, 단위근이 존재하지 않 는다는 귀무가설을 단위근이 존재한다는 대립가설에 대해 검정하는 KPSS 검정을 실시한다. KPSS 검 정은 상수가 포함되는 경우 $(\mathrm{C})$ 와 확률추세 주변에서 상수를 가진 경우 $(\mathrm{T})$ 의 두 가지 다른 모형으로 추 


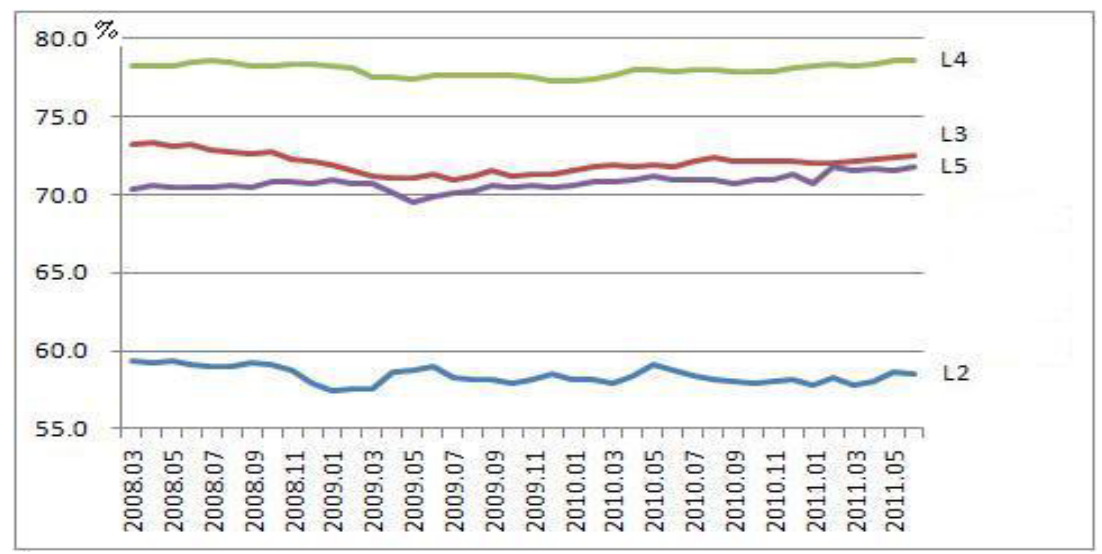

Figure 2.1. Transition in employment rates by generations

Table 2.1. Basic statistics

\begin{tabular}{ccccc}
\hline & $L_{2}$ & $L_{3}$ & $L_{4}$ & $L_{5}$ \\
\hline Mean & 58.4050 & 72.0300 & 78.0025 & 70.7650 \\
Median & 58.3000 & 72.0500 & 78.0000 & 70.7000 \\
Maximum & 59.4000 & 73.3000 & 78.6000 & 71.8000 \\
Minimum & 57.5000 & 71.0000 & 77.3000 & 69.5000 \\
Std.Dev. & 0.5267 & 0.6342 & 0.3860 & 0.4918 \\
Skewness & 0.2509 & 0.2227 & -0.2089 & 0.1900 \\
Kurtosis & 1.9451 & 2.2670 & 1.9512 & 3.5201 \\
Jarque-Bera & 2.2743 & 1.2263 & 2.1242 & 0.6914 \\
Probability & 0.3207 & 0.5417 & 0.3457 & 0.7077 \\
Sum & 2336.2000 & 2881.2000 & 3120.1000 & 2830.6000 \\
Sum Sq. Dev. & 10.8190 & 15.6840 & 5.8098 & 9.4310 \\
Observations & 40 & 40 & 40 & 40 \\
\hline
\end{tabular}

Table 2.2. KPSS tests

\begin{tabular}{|c|c|c|c|c|}
\hline & \multicolumn{2}{|c|}{ 수준 } & \multicolumn{2}{|c|}{ 차분 } \\
\hline & $\mathrm{C}$ & $\mathrm{T}$ & $\mathrm{C}$ & $\mathrm{T}$ \\
\hline$L_{2}$ & 0.4070 & 0.1208 & 0.2319 & 0.1136 \\
\hline$L_{3}$ & 0.2078 & $0.1811^{*}$ & $0.4675^{*}$ & 0.0960 \\
\hline$L_{4}$ & 0.1891 & $0.1873^{*}$ & 0.3009 & 0.1211 \\
\hline$L_{5}$ & $0.5140^{*}$ & $0.1545^{*}$ & 0.1478 & 0.0763 \\
\hline \multicolumn{5}{|c|}{ 임계치 } \\
\hline $1 \%$ & 0.739 & 0.216 & 0.739 & 0.216 \\
\hline $5 \%$ & 0.463 & 0.146 & 0.463 & 0.146 \\
\hline
\end{tabular}

정된다 (Kwiatkowski 등, 1992).

결과는 Table 2.2 와 같으며, 본 연구에서 $*, * *$ 는 각각 유의수준 $5 \%, 1 \%$ 에서 통계적으로 유의함을 뜻한 다. 수준변수에서는 귀무가설의 성립 여부가 엇갈리지만 차분변수에서는 30 대 고용률에서 상수가 포함 되는 경우에서만 귀무가설이 $5 \%$ 유의수준에서 기각된다. $\mathrm{KPSS}$ 검정결과는 예상과는 달리 자료의 정 
Table 2.3. ADF tests

\begin{tabular}{|c|c|c|c|c|c|c|}
\hline & \multicolumn{3}{|c|}{ 수준 } & \multicolumn{3}{|c|}{ 차분 } \\
\hline & 시차 & $\mathrm{C}$ & $\mathrm{T}$ & 시차 & $\mathrm{C}$ & $\mathrm{T}$ \\
\hline$L_{2}$ & 0 & $-3.3957^{*}$ & $-3.5894^{*}$ & 0 & $-5.6648^{* *}$ & $-5.6559^{* *}$ \\
\hline$L_{3}$ & 0 & -1.7669 & -1.1867 & 0 & $-5.2649^{* *}$ & $-6.2058^{* *}$ \\
\hline$L_{4}$ & 0 & -1.1399 & -0.9870 & 0 & $-5.0581^{* *}$ & $-5.1462^{* *}$ \\
\hline$L_{5}$ & 1 & -1.4508 & -2.4913 & 0 & $-8.5901^{* *}$ & $-8.6534^{* *}$ \\
\hline
\end{tabular}

Table 2.4. Lag selection

\begin{tabular}{ccccccc}
\hline lag & LogL & LR & FPE & AIC & SC & HQ \\
\hline 0 & -56.242 & NA & 0.0004 & 3.4424 & 3.6202 & 3.5038 \\
1 & 17.9841 & 127.2447 & $1.33 \mathrm{E}-05$ & 0.1152 & $1.0040 \star$ & $0.4220 \star$ \\
2 & 35.8409 & $26.5300 \star$ & $1.24 \mathrm{E}-05 \star$ & $0.0091 \star$ & 1.6089 & 0.5613 \\
3 & 46.0018 & 12.7738 & $1.92 \mathrm{E}-05$ & 0.342854 & 2.6536 & 1.1404 \\
4 & 63.4618 & 17.9589 & $2.18 \mathrm{E}-05$ & 0.259324 & 3.2811 & 1.3025 \\
5 & 80.7342 & 13.8179 & $2.98 \mathrm{E}-05$ & 0.186616 & 3.9195 & 1.4752 \\
\hline
\end{tabular}

Table 2.5. Trace-ME tests

\begin{tabular}{|c|c|c|c|c|c|c|c|}
\hline \multirow{2}{*}{ rank } & \multirow{2}{*}{ eigenvalue } & \multicolumn{3}{|c|}{ Trace } & \multicolumn{3}{|c|}{$\mathrm{ME}$} \\
\hline & & $5 \%$ & $1 \%$ & Trace statistic & $5 \%$ & $1 \%$ & Max-Eigen statistic \\
\hline$r=0$ & 0.5396 & 54.0790 & 61.2669 & 50.3059 & 28.5881 & 33.7329 & 29.4715 \\
\hline$r \leq 1$ & 0.2352 & 35.1928 & 41.1950 & 20.8345 & 22.2996 & 27.0678 & 10.1893 \\
\hline$r \leq 2$ & 0.2205 & 20.2618 & 25.0781 & 10.6452 & 15.8921 & 20.1612 & 9.4633 \\
\hline$r \leq 3$ & 0.0306 & 9.1646 & 12.7608 & 1.1819 & 9.1646 & 12.7608 & 1.1819 \\
\hline
\end{tabular}

상성을 확실히 결정해 주지 않으므로 전통적인 단위근 검정법인 $\mathrm{ADF}$ 검정을 추가로 실시하며, 적정 시 차는 AIC(Akaike information criterion) 기준에 따라 결정한다. 시차의 길이가 알려져 있지 않은 경 우 Schwert (1987) 또 Diebold와 Nerlove (1989)의 방법을 사용할 수 있다. $\mathrm{Ng}$ 와 Perron (1995)은 시차가 너무 짧으면 모형의 왜곡이 심하고, 너무 길면 검정력이 감소하므로 모형에 포함된 마지막 시 차 계수가 통계적으로 유의할 때까지 시차를 한 개씩 감소시키는 연속검정 방식이 AIC나 $\mathrm{SC}$ (Schwarz criterion)같은 정보 기준 검정법보다 우월하다는 연구결과를 보였다. KPSS 검정에서와 같이 상수가 포함되는 모형과 추세까지 포함되는 모형에 대한 검정결과는 Table 2.3 과 같다. 거의 모든 수준변수에 서 단위근이 존재한다는 귀무가설이 성립되지만 차분변수에서는 모두 $1 \%$ 유의수준에서 기각되므로 모 든 변수들을 1 차 적분변수로 간주한다. 참고로 차분변수들에 대한 상관분석도 경기변수와 고용률 간 상 관관계가 0.496 으로 통계적으로 매우 유의한데 반해 실업률과는 -0.243 으로 유의하지 않은 것으로 나 타났다.

연령대별 고용 간에 장기적 상관관계가 존재하는지 확인하기 위해 1 차 적분변수들의 위수검정 및 정규 상관계수를 사용하여 최우추정법을 적용하는 Johansen 공적분 검정을 실시하기로 한다. 벡터자기회귀 모형을 추정하여 Table 2.4 의 LR(sequential modified LR test statistic), FPE(final prediction error), 또 $\mathrm{AIC}$ 기준을 근거로 시차를 2 로 정하며 따라서 공적분 검정의 적정 시차는 1 이 된다.

Trace 통계량과 $\mathrm{ME}$ (maximum eigenvalue) 통계량에 근거한 공적분 검정결과는 Table 2.5 와 같다. 원 계열에 확정적 추세가 없고, 방정식은 상수항만 있는 경우를 상정한 결과 공적분 위수가 0 이라는 귀무가 설을 기각하지 못하므로 장기적 관계가 존재하지 않는 것으로 검정되었다. 


\section{3. 인과성 검정}

변수들 간에 공적분이 존재하지 않으므로 차분 벡터자기회귀모형(VAR)을 사용하여 연관성을 추정한 다. 각 연령대별 고용률에 대한 추정결과는 아래와 같으며, ( )안은 $t$ 값이다.

$$
\begin{aligned}
& \Delta L_{2} t=-0.0047+0.2155 \Delta L_{2 t-1}-0.2626 \Delta L_{2 t-2}+0.1872 \Delta L_{3 t-1}-0.1131 \Delta L_{3 t-2} \\
& \begin{array}{llll}
(-0.0745) & (1.2053) \quad(-1.4279) \quad(0.5531) \quad(-0.3317)
\end{array} \\
& -0.6480 \Delta L_{4 t-1}+0.7057 \Delta L_{4 t-2}-0.5630 \Delta L_{5 t-1}-0.0854 \Delta L_{5 t-2} \\
& \begin{array}{llll}
(-1.6671) \quad(1.7103) \quad(-2.2712) \quad(-0.3533)
\end{array} \\
& \mathrm{R}^{2}=0.2768, \quad F \text {-statistic }=1.3393,
\end{aligned}
$$

Log likelihood $=-10.2853$, Akaike AIC $=1.0425$, Schwarz $\mathrm{SC}=1.4343$

$$
\begin{aligned}
& \Delta L_{3 t}=-0.0015+0.0764 \Delta L_{2 t-1}+0.0815 \Delta L_{2 t-2}+0.2351 \Delta L_{3 t-1}+0.1581 \Delta L_{3 t-2} \\
& \begin{array}{llll}
(-0.0414) & (0.7460) \quad(0.7740) & (1.2139) & (0.8096)
\end{array} \\
& -0.2021 \Delta L_{4 t-1}+0.0348 \Delta L_{4 t-2}-0.1016 \Delta L_{5 t-1}+0.0983 \Delta L_{5 t-2} \\
& \begin{array}{llll}
(-0.9085) & (0.1474) \quad(-0.7163) & (0.7107)
\end{array} \\
& \mathrm{R}^{2}=0.1914, \quad F \text {-statistic }=0.8283
\end{aligned}
$$

Log likelihood $=10.3601$, Akaike AIC $=-0.0735$, Schwarz $\mathrm{SC}=0.3183$

$$
\begin{aligned}
& \Delta L_{4 t}=0.0308-0.0899 \Delta L_{2 t-1}+0.1377 \Delta L_{2 t-2}+0.2344 \Delta L_{3 t-1}+0.3075 \Delta L_{3 t-2} \\
& \text { (1.0675) (-1.0963) (1.6338) (1.5112) (1.9667) } \\
& +0.0586 \Delta L_{4 t-1}-0.0798 \Delta L_{4 t-2}-0.0567 \Delta L_{5 t-1}-0.0520 \Delta L_{5 t-2} \\
& \begin{array}{llll}
(0.3289) \quad(-0.4218) & (-0.4991) \quad(-0.4689)
\end{array} \\
& \mathrm{R}^{2}=0.3471, \quad F \text {-statistic }=1.8610,
\end{aligned}
$$

Log likelihood $=18.5765$, Akaike AIC $=-0.5177$, Schwarz $\mathrm{SC}=-0.1258$

$$
\begin{aligned}
& \Delta L_{5 t}=0.0464-0.1605 \Delta L_{2 t-1}-0.0043 \Delta L_{2 t-2}+0.1759 \Delta L_{3 t-1}-0.0637 \Delta L_{3 t-2} \\
& \begin{array}{llll}
(0.9714)(-1.1846) \quad(-0.0309) \quad(0.6860) \quad(-0.2466)
\end{array} \\
& +0.4599 \Delta L_{4 t-1}+0.5633 \Delta L_{4 t-2}-0.5195 \Delta L_{5 t-1}-0.0712 \Delta L_{5 t-2} \\
& (1.5619) \quad(1.8019) \quad(-2.7662) \quad(-0.3886) \\
& \mathrm{R}^{2}=0.3633, \quad F \text {-statistic }=1.9967,
\end{aligned}
$$

Log likelihood $=-0.0116$, Akaike AIC $=0.4871$, Schwarz $\mathrm{SC}=0.8790$

위의 추정결과를 보면 변수들 간 유의한 관계는 많이 존재하지 않는다. 벡터자기회귀모형은 각 방정식 이 시차관계를 포함하고 있으므로 개별 계수에 대한 해석은 큰 의미가 없는 것으로 알려져 있다. 따라 서 연령대별 고용 간 전반적 연관성을 파악하기 위해 $F$ 검정으로 변수들의 시차관계를 동시에 고려하 는 Granger 인과성 검정을 실시한다. 인과관계의 검정시차는 임의로 짧게 잡는 경향이 있으나 이는 통 계적 근거가 없으며 현실을 오도할 우려가 있으므로 본 연구에서는 이러한 가능성을 배제하기 위해 유의 수준 $5 \%$ 에서 통계적으로 유의한 인과관계가 존재하는 시차까지 모두 검정하기로 한다. Table 3.1 에서 보듯이 시차에 따라 인과관계가 존재하지 않는다는 귀무가설의 기각 여부가 달라질 수 있으며, 유의수준 
Table 3.1. Granger test results

\begin{tabular}{|c|c|c|c|c|c|c|c|c|}
\hline \multirow{2}{*}{$\begin{array}{c}\text { Null } \\
\text { Hypothesis }\end{array}$} & \multicolumn{2}{|c|}{ 시차 : 1} & \multicolumn{2}{|c|}{ 시차 : 2} & \multicolumn{2}{|c|}{ 시차: 3} & \multicolumn{2}{|c|}{ 시차 : 4} \\
\hline & $F$-stat & $P$ & $F$-stat & $P$ & $F$-stat & $P$ & $F$-stat & $P$ \\
\hline$L_{3} \nrightarrow L_{2}$ & 0.1212 & 0.7298 & 0.5839 & 0.5634 & 0.6731 & 0.5753 & 0.4583 & 0.7656 \\
\hline$L_{2} \nrightarrow L_{3}$ & 1.3779 & 0.2482 & 0.4132 & 0.6649 & 0.5456 & 0.6549 & 1.6231 & 0.1972 \\
\hline$L_{4} \nrightarrow L_{2}$ & 0.0821 & 0.7761 & 1.4358 & 0.2524 & 1.0541 & 0.3832 & 0.6058 & 0.6619 \\
\hline$L_{2} \nrightarrow L_{4}$ & 0.8528 & 0.3619 & 1.3361 & 0.2767 & 1.6646 & 0.1956 & 1.6970 & 0.1798 \\
\hline$L_{5} \nrightarrow L_{2}$ & 0.4719 & 0.4965 & 2.3048 & 0.1156 & 1.5148 & 0.2308 & 2.1251 & 0.1052 \\
\hline$L_{2} \nrightarrow L_{5}$ & 0.1659 & 0.6862 & 1.1014 & 0.3443 & 0.5395 & 0.6589 & 0.6088 & 0.6598 \\
\hline$L_{4} \nrightarrow L_{3}$ & 1.4959 & 0.2293 & 0.3087 & 0.7365 & 0.3107 & 0.8175 & 0.3879 & 0.8154 \\
\hline$L_{3} \nrightarrow L_{4}$ & 7.0162 & $0.0119^{*}$ & 3.9361 & $0.0293^{*}$ & 4.6231 & $0.0090^{* *}$ & 2.5499 & 0.0621 \\
\hline$L_{5} \nrightarrow L_{3}$ & 0.4456 & 0.5087 & 2.2681 & 0.1194 & 1.2808 & 0.2989 & 1.1873 & 0.3388 \\
\hline$L_{3} \nrightarrow L_{5}$ & 0.3782 & 0.5424 & 0.3676 & 0.6952 & 0.6721 & 0.5759 & 1.2465 & 0.3151 \\
\hline$L_{5} \nrightarrow L_{4}$ & 0.4528 & 0.5053 & 0.8843 & 0.4226 & 0.5380 & 0.6599 & 0.9408 & 0.4449 \\
\hline$L_{4} \nrightarrow L_{5}$ & 1.1244 & 0.2960 & 2.2856 & 0.1176 & 3.3229 & $0.0329^{*}$ & 2.3727 & 0.0773 \\
\hline
\end{tabular}

\begin{tabular}{|c|c|c|c|c|c|c|c|c|c|c|c|c|c|}
\hline$L_{2}, L_{3}(-1)$ & $L_{2}, L_{3}{ }^{(+i)}$ & $i \quad$ lag & lead & $L_{2}, L_{4}(-i)$ & $L_{2} \cdot L_{4}(+i)$ & 8 & lag & lead & $L_{2} \cdot L_{5}(-i)$ & $L_{2}, L_{5}(+i)$ & i & lag & lead \\
\hline 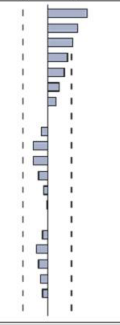 & 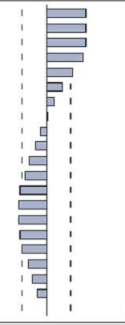 & 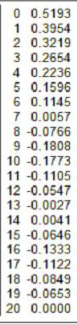 & 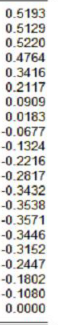 & 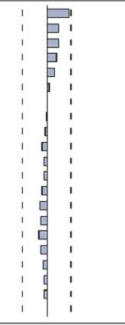 & 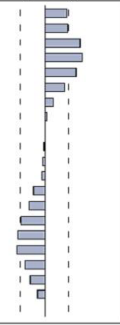 & \begin{tabular}{|l}
0 \\
1 \\
2 \\
3 \\
4 \\
5 \\
6 \\
7 \\
7 \\
8 \\
9 \\
10 \\
11 \\
12 \\
13 \\
14 \\
15 \\
16 \\
17 \\
11 \\
19 \\
20 \\
\end{tabular} & 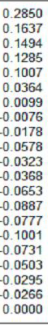 & 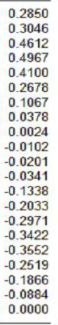 & $\begin{array}{l}1 \\
5 \\
5\end{array}$ & 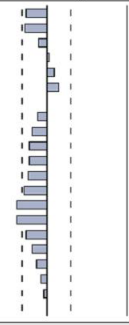 & \begin{tabular}{|c|c}
$\mathbf{8}$ \\
9 \\
10 \\
11 \\
12 \\
13 \\
14 \\
15 \\
16 \\
17 \\
18 \\
19 \\
20 \\
19
\end{tabular} & 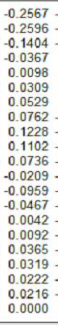 & 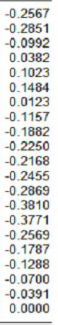 \\
\hline$L_{3} \cdot L_{4}(-i)$ & $L_{3} \cdot L_{4}{ }^{(+i)}$ & $\begin{array}{ll}i & \text { lag } \\
\end{array}$ & lead & $L_{3} \cdot L_{5}(-i)$ & $\bar{L}_{3}, L_{5}(+i)$ & i & lag & lead & $L_{4}, L_{5}(-i)$ & $L_{4}, L_{5}(+i)$ & $\bar{i}$ & lag & lead \\
\hline 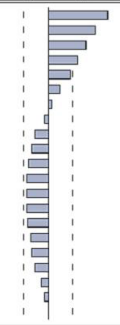 & 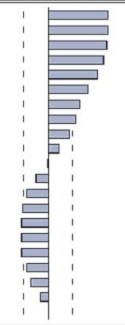 & 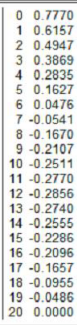 & 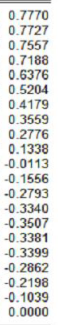 & 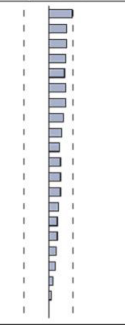 & 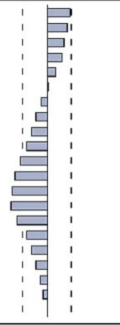 & $\begin{array}{l}10 \\
10 \\
11 \\
12 \\
13 \\
14 \\
15 \\
16 \\
17 \\
18 \\
19 \\
20\end{array}$ & $\begin{array}{l}0.3101 \\
0.2457 \\
0.22394 \\
0.2181 \\
0.22078 \\
0.2218 \\
0.2209 \\
0.1890 \\
0.1715 \\
0.1793 \\
0.1519 \\
0.1607 \\
0.1580 \\
0.1268 \\
0.1147 \\
0.11082 \\
0.1063 \\
0.0678 \\
0.0590 \\
0.0348 \\
0.0000\end{array}$ & 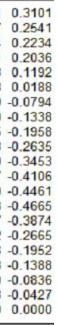 & 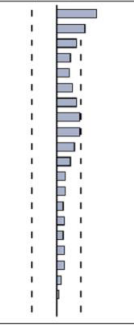 & 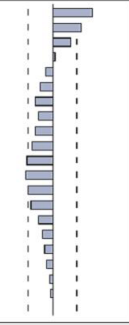 & & 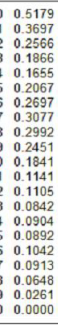 & 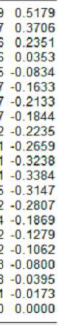 \\
\hline
\end{tabular}

Figure 3.1. Cross correlation analysis

$5 \%$ 내에서 통계적 유의성을 일관되게 유지하는 경우는 짙게 표시된 바와 같이 30 대 고용이 40 대 고용 에 영향을 미치는 것으로 나타난다.

연구기간 동안 연령대별 고용률 간 연관성은 일반적인 인식과는 달리 미약한 것으로 검정되어 고용의 대 체관계 및 보완관계는 거의 존재하지 않은 것으로 나타난다. 인과관계는 교차상관 분석을 통해서도 식 별될 수 있으므로 위의 검정결과를 보완해 보기로 한다. $t$ 기의 $X_{1}$ 과 $t-i$ 까지 $X_{2}$ 와의 교차상관계수 중 시차 $i=0$ 일 때 상관계수가 가장 크면 두 변수는 동행, $i>0$ 이면 $X_{2}$ 가 $X_{1}$ 을 $i$ 시차 선행, 또 $i<0$ 이 면 $X_{1}$ 이 $X_{2}$ 를 $i$ 시차 선행한다. 교차상관계수가 0.3 보다 작거나 큰 시차에서 0.5 에 미치지 못하면 연관 
Table 3.2. Relative importance of employment rate $\left(L_{4}\right)$

\begin{tabular}{cccccc}
\hline 기간 & S.E. & $L_{2}$ & $L_{3}$ & $L_{4}$ & $L_{5}$ \\
\hline 1 & 0.3673 & 0 & 0 & 100 & 0 \\
3 & 0.4226 & 8.4008 & 18.2180 & 72.8108 & 0.5704 \\
5 & 0.4316 & 12.3315 & 18.3022 & 67.8664 & 1.5000 \\
7 & 0.4322 & 12.9061 & 18.5009 & 67.0153 & 1.5777 \\
9 & 0.4323 & 12.9790 & 18.5400 & 66.9050 & 1.5760 \\
\hline
\end{tabular}

Table 3.3. Long-run response to changes in $L_{2}$

\begin{tabular}{ccccc}
\hline 기간 & $L_{2}$ & $L_{3}$ & $L_{4}$ & $L_{5}$ \\
\hline \multirow{2}{*}{1} & $0.3673^{* *}$ & 0.0190 & 0.0537 & 0.0054 \\
& $(0.0427)$ & $(0.0345)$ & $(0.0270)$ & $(0.0457)$ \\
\hline \multirow{2}{*}{3} & -0.0119 & 0.0524 & 0.0532 & 0.0293 \\
& $(0.0747)$ & $(0.0400)$ & $(0.0339)$ & $(0.0573)$ \\
\hline \multirow{2}{*}{5} & -0.0075 & -0.0005 & 0.0168 & 0.0473 \\
& $(0.0357)$ & $(0.0203)$ & $(0.0231)$ & $(0.0315)$ \\
\hline \multirow{2}{*}{7} & 0.0158 & 0.0042 & -0.0091 & -0.0036 \\
& $(0.0232)$ & $(0.0120)$ & $0.0129)$ & $(0.0172)$ \\
\hline \multirow{2}{*}{9} & -0.0010 & 0.0039 & 0.0050 & -0.0011 \\
& $(0.0128)$ & $(0.0055)$ & $(0.0084)$ & $(0.0089)$ \\
\hline
\end{tabular}

성이 없는 것으로 간주한다. Figure 3.1에서 lag와 lead의 상관계수는 각각 좌측과 우측 그래프에 나타 나며, lag은 앞의 변수가 뒤의 변수를 후행함을, 그리고 lead는 선행함을 의미한다. 교차상관분석 결과 $L_{2} \rightarrow L_{4}$ 에서 시차 3 일 때 상관계수가 0.4967 로 가장 높아 20 대 고용이 40 대 고용에 영향을 미치는 것 으로 나타난다. $L_{2}$ 와 $L_{3}, L_{3}$ 와 $L_{4}$ 또 $L_{4}$ 와 $L_{5}$ 는 각각 동행하며, 그 외는 상관관계가 없어 앞에서와 같 이 전반적으로 변수들 간 연관관계는 약한 것으로 나타난다. Granger 인과관계 검정과 교차상관 분석 의 결과가 다를 경우는 관례적으로 전자를 따른다.

참고로 40 대 고용률의 설명력 분포를 보면 Table 3.2 에서 보듯이 자체 설명력이 초기에는 전부였으나 시간이 가면서 차츰 감소하여 장기적으로는 $67 \%$ 정도를 유지한다. 40 대 고용의 변화에 대해 20 대와 30 대 고용은 초기와는 달리 시간이 흐르면서 설명력이 차츰 증가하여 장기적으로는 각각 $13 \%$ 와 $19 \%$ 정도의 비중을 차지하는 것으로 계산되어 앞의 두 분석결과를 뒷받침하는 것으로 나타난다.

Granger 인과관계 검정은 변수들 간 관계에 대한 부호는 제공해 주지 않으므로 동적 관계의 파악을 위 해 충격반응함수를 이용한다. 공적분이 존재하지 않으므로 벡터자기회귀모형에 근거해 충격반응함수를 구하며 각 예측기간에 대한 표준편차를 계산한다. 벡터자기회귀모형에서는 오차항의 분산행렬이 대각 행렬이 아닌 상태여서 반응을 해석하기 어려우므로 오차항을 직교화하여 다른 오차항들 간 공분산이 0 이 되도록 모형을 변환한다. 오차항의 분산행렬을 직교화하는 데는 Cholesky 분할이 주로 사용되어 모형이 축차형으로 표현된다. 따라서 $j$ 번째 방정식의 오차항에 주어진 충격은 $j$ 번째 방정식 이하의 종 속변수들에게 영향을 주어 변수들의 배열 순서가 달라지면 시간에 걸친 반응이 달라진다. 변수를 배 열하는 데는 이들의 인과관계가 어떻게 설정되는지 고려되어야 하나 이론적 근거는 불충분하다 (Yoo, 2000). Lee (2005)은 변수의 배열 순서에 관계없이 동일한 결과를 가져오기 위한 시도로 구조형 VAR$\mathrm{GARCH}$ 모형을 사용한 바 있다. 변수들의 인과관계가 명확히 식별되지 않으므로 $L_{2}, L_{3}, L_{4}, L_{5}$ 의 연 령대 순서로 놓으며 배열을 달리하여도 질적 차이는 발생하지 않는다. 먼저 20 대 고용률의 변화에 따라 다른 연령대 고용률이 보이는 장기적 반응은 Table 3.3 에서 보는 바와 같이 통계적으로 유의하지 않다. 
Table 3.4. Long-run response to changes in $L_{3}$

\begin{tabular}{|c|c|c|c|c|c|c|}
\hline \multirow{2}{*}{ 기간 } & \multicolumn{4}{|c|}{ 장기적 반응 } & \multicolumn{2}{|c|}{ 누적 반응 } \\
\hline & $L_{2}$ & $L_{3}$ & $L_{4}$ & $L_{5}$ & $L_{3}$ & $L_{4}$ \\
\hline \multirow{2}{*}{1} & 0 & $0.2094^{* *}$ & 0.0325 & 0.0796 & $0.2094^{* *}$ & 0.0325 \\
\hline & 0.0000 & $(0.0243)$ & $(0.0260)$ & $(0.0448)$ & $(0.0243)$ & $(0.0260)$ \\
\hline \multirow{2}{*}{2} & -0.0267 & 0.0346 & 0.04647 & 0.0104 & $0.2439^{* *}$ & 0.0790 \\
\hline & $(0.0730)$ & $(0.0039)$ & $(0.0308)$ & $(0.0555)$ & $(0.0477)$ & $(0.0415)$ \\
\hline \multirow{2}{*}{3} & -0.0428 & 0.0377 & $0.0703^{*}$ & 0.0256 & $0.2816^{* *}$ & $0.1492^{* *}$ \\
\hline & $(0.0733)$ & $(0.0385)$ & $(0.0318)$ & $(0.0568)$ & $(0.0677)$ & $(0.0539)$ \\
\hline \multirow{2}{*}{4} & -0.0271 & -0.0053 & 0.0181 & 0.0559 & $0.2763^{* *}$ & $0.1673^{* *}$ \\
\hline & $(0.0466)$ & $(0.0265)$ & $(0.0249)$ & $(0.0401)$ & $(0.0855)$ & $(0.0643)$ \\
\hline \multirow{2}{*}{5} & 0.0044 & -0.0052 & -0.0022 & 0.01826 & $0.2711^{* *}$ & $0.16515^{*}$ \\
\hline & $(0.0349)$ & $(0.0243)$ & $(0.0237)$ & $(0.0322)$ & $(0.0976)$ & $(0.0737)$ \\
\hline \multirow{2}{*}{6} & 0.00678 & 0.0008 & -0.0125 & -0.0055 & $0.2719^{* *}$ & 0.1527 \\
\hline & $(0.0270)$ & $(0.0151)$ & $(0.0171)$ & $(0.0227)$ & $(0.1022)$ & $(0.0786)$ \\
\hline \multirow{2}{*}{7} & 0.0091 & 0.0050 & -0.0026 & -0.0061 & $0.2769^{* *}$ & 0.1500 \\
\hline & $(0.0173)$ & $(0.0091)$ & $(0.0118)$ & $(0.0146)$ & $(0.1035)$ & $(0.0805)$ \\
\hline \multirow{2}{*}{8} & -0.0022 & 0.0027 & 0.0030 & -0.0054 & $0.2797^{* *}$ & 0.1530 \\
\hline & $(0.0127)$ & $(0.0060)$ & $(0.0087)$ & $(0.0104)$ & $(0.1037)$ & $(0.0801)$ \\
\hline \multirow{2}{*}{9} & -0.0032 & 0.00126 & 0.0046 & 0.0036 & $0.2809^{* *}$ & $0.1577^{*}$ \\
\hline & $(0.0102)$ & $(0.0043)$ & $(0.0064)$ & $(0.0071)$ & $(0.1042)$ & $(0.0798)$ \\
\hline \multirow{2}{*}{10} & -0.0026 & -0.0014 & 0.0012 & 0.0029 & $0.2795^{* *}$ & $0.1589^{*}$ \\
\hline & $(0.0068)$ & $(0.0033)$ & $(0.0046)$ & $(0.0054)$ & $(0.1052)$ & $(0.0800)$ \\
\hline
\end{tabular}

30 대 고용률의 충격에 다른 연령대 고용률이 보이는 장기적 반응을 보면 Table 3.4 에 요약된 바와 같이 40 대 고용률만이 통계적으로 유의한 반응을 보인다. 따라서 벡터자기회귀모형의 추정 및 Granger 인과 관계 검정과 일관성 있는 결과를 보인다. 30 대 고용률 한 단위 충격에 40 대 고용률이 양의 반응을 보이 는데는 3 기간이 걸리는 것으로 계산된다. Table 3.4 의 우측은 30 대 고용률의 충격에 따른 자체 및 40 대 고용률이 보이는 누적반응이다. 40 대 고용률이 보이는 장기적 반응은 기간 3 부터 매우 유의하며 기간 6 부터 다소 약해졌다가 기간 9 이후 다시 유의해진다.

\section{4. $\mathrm{FPE}$ 검정}

인과관계의 결과는 시차의 선택에 결정적인 영향을 받지만 일반적으로 시차의 선택은 임의적이어서 추 정과정에서 오류나 비효율성이 발생할 가능성이 있다. 따라서 Akaike (1969)의 최종예측오차(FPE) 기 준과 Granger 검정법을 결합한 Hsiao (1981)의 검정 절차를 이용하여 적절한 시차를 결정하며, 앞의 Granger 검정법과 비교, 분석해 보고자 한다. Thornton과 Batten (1985)는 시차의 선택에 Hsiao 방법 이 가장 우수함을 보였다.

Table 4.1은 20대 고용률이 종속변수일 때 다른 연령대의 고용률을 독립변수로 추가한 모형의 $\mathrm{FPE}$ 로 최소값은 짙게 표시되어 이를 통해 Hsiao 인과관계를 판별한다. 20 대 고용률로만 구성된 벡터자기회귀 모형의 $\mathrm{FPE}$ 는 최소값 0.0093237 을 가지며, 30 대 고용률이 독립변수로 추가된 벡터자기회귀모형의 최 소 FPE 0.0382853 보다 작으므로 30 대 고용은 20 대 고용에 영향을 미치지 않는다. 또한 40 대 고용률이 나 50대 고용률을 독립변수로 추가한 벡터자기회귀모형의 최소 FPE인 0.0503827 과 0.0464389 보다도 역시 작아 40 대와 50 대 고용은 각각 20 대 고용에 영향을 미치지 않는 것으로 나타난다. 
Table 4.1. FPE tests $\left(L_{2}\right)$

\begin{tabular}{ccccc}
\hline 시차 & FPE of 20대 & & FPE of 30대 & \\
\hline 1 & 0.1204314 & 0.3486505 & FPE of 40 대 $^{3)}$ & FPE of 50대 $^{4)}$ \\
3 & 0.1174425 & 0.3336393 & 0.3490284 & 0.3452977 \\
5 & 0.1147745 & 0.3586128 & 0.3075664 & 0.3092511 \\
7 & 0.1034533 & 0.3091844 & 0.2616116 & 0.2966991 \\
9 & 0.0846417 & 0.2390165 & 0.1753820 & 0.2598189 \\
11 & 0.0848328 & 0.2428094 & 0.1250484 & 0.0917651 \\
12 & 0.0832293 & $0.03828532 \star$ & $0.0503827 \star$ & $0.0464389 \star$ \\
13 & 0.0780111 & & & \\
15 & 0.0767495 & & & \\
17 & 0.0518169 & & & \\
19 & $0.0093237 \star$ & & & \\
\hline
\end{tabular}

1) 20 대 $=f\left(20\right.$ 대 t-i $\left._{t}\right)$

2) 20 대 $=f\left(20\right.$ 대 $_{t-19}, 30$ 대 $\left._{t-i}\right)$

3) 20 대 $=f\left(20\right.$ 대 $_{t-19}, 40$ 대 $\left._{t-i}\right)$

4) 20 대 $=f\left(20\right.$ 대 $_{t-19}, 50$ 대 $\left._{t-i}\right)$

Table 4.2. FPE tests $\left(L_{3}\right)$

\begin{tabular}{|c|c|c|c|c|}
\hline 시차 & FPE of 30 대 $^{1)}$ & FPE of 20 대 $^{2)}$ & FPE of 40 대 $\left.^{3}\right)$ & FPE of 50 대 ${ }^{4)}$ \\
\hline 1 & 0.0401954 & 0.1124538 & 0.1121001 & 0.1153306 \\
\hline 3 & 0.0401522 & 0.1154462 & 0.1180764 & 0.1079227 \\
\hline 5 & 0.0390443 & 0.0914308 & 0.1063709 & 0.1001365 \\
\hline 7 & 0.0402933 & 0.0896010 & 0.1212173 & 0.1073403 \\
\hline 9 & 0.0336831 & 0.0542525 & 0.0717040 & 0.0893824 \\
\hline 11 & 0.0356136 & 0.0486888 & 0.0251415 & 0.0439265 \\
\hline 12 & 0.0269297 & $0.0219553 \star$ & $0.0047030 \star$ & $0.0190715 \star$ \\
\hline 13 & 0.0255406 & & & \\
\hline 15 & 0.0204425 & & & \\
\hline 17 & 0.0070801 & & & \\
\hline 19 & $0.0017164 \star$ & & & \\
\hline
\end{tabular}

1) 30 대 $=f\left(30\right.$ 대 $\left.{ }_{t-i}\right)$

2) 30 대 $=f\left(30\right.$ 대 $_{t-19}, 20$ 대 $\left._{t-i}\right)$

3) 30 대 $=f\left(30\right.$ 대 $t-19,40$ 대 $\left.{ }_{t-i}\right)$

4) 30 대 $=f\left(30\right.$ 대 $_{t-19}, 50$ 대 $\left._{t-i}\right)$

Table 4.2는 30 대 고용률이 종속변수일 때 다른 연령대 고용률을 각각 독립변수로 추가한 모형의 $\mathrm{FPE}$ 이다. 다른 연령대 고용률이 각각 독립변수로 추가된 벡터자기회귀모형의 $\mathrm{FPE}$ 최소값이 30 대 고 용률로만 구성된 모형의 $\mathrm{FPE}$ 최소값을 모두 초과하므로 다른 연령대 고용은 각각 30 대 고용에 영향을 미치지 않는 것으로 파악된다.

위에서와 같은 방법으로 40 대 고용률과 50 대 고용률에 대해서도 분석하였으며 결과는 각각 Table 4.3 또 Table 4.4 와 같다. 각 종속변수의 최소 $\mathrm{FPE}$ 가 추가되는 다른 독립변수들의 최소 $\mathrm{FPE}$ 보다 작으므 로 다른 연령대의 고용은 각각 40 대 고용, 또 50 대 고용에 영향을 미치지 않는다. 따라서 Hsiao 인과관 계 검정결과에 따르면 각 연령대별 고용 간에는 연관관계가 존재하지 않는 것으로 판명된다. 
Table 4.3. FPE tests $\left(L_{4}\right)$

\begin{tabular}{|c|c|c|c|c|}
\hline 시차 & FPE of 40 대 $^{1)}$ & FPE of 20 대 $^{2)}$ & FPE of 30 대 $^{3)}$ & FPE of 50 대 ${ }^{4)}$ \\
\hline 1 & 0.0327722 & 0.0929927 & 0.0796687 & 0.0940131 \\
\hline 3 & 0.0337467 & 0.0877207 & 0.0699735 & 0.0970988 \\
\hline 5 & 0.0290566 & 0.0720254 & 0.0703742 & 0.0735496 \\
\hline 7 & 0.0311925 & 0.0781529 & 0.0677960 & 0.0728807 \\
\hline 9 & 0.0300416 & 0.0456005 & 0.0529462 & 0.0495972 \\
\hline 11 & 0.0221378 & 0.0154315 & 0.0245293 & 0.0457966 \\
\hline 12 & 0.0229750 & $0.0072018 \star$ & $0.0122499 \star$ & $0.0069251 \star$ \\
\hline 13 & 0.0114410 & & & \\
\hline 15 & 0.0091527 & & & \\
\hline 17 & 0.0088402 & & & \\
\hline 19 & $0.0000132 \star$ & & & \\
\hline
\end{tabular}

1) 40 대 $=f\left(40\right.$ 대 $\left._{t-i}\right)$

2) 40 대 $=f\left(40\right.$ 대 $_{t-19}, 20$ 대 $\left._{t-i}\right)$

3) 40 대 $=f\left(40\right.$ 대 $_{t-19}, 30$ 대 $_{t-i}$ )

4) 40 대 $=f\left(40\right.$ 대 $_{t-19}, 50$ 대 $\left._{t-i}\right)$

Table 4.4. FPE tests $\left(L_{5}\right)$

\begin{tabular}{ccccc}
\hline 시차 & FPE of 50대 ${ }^{1)}$ & FPE of 20대 ${ }^{2)}$ & FPE of 30 대 $^{3)}$ & FPE of 50대 $^{4)}$ \\
\hline 1 & 0.0901912 & 0.2607824 & 0.2592603 & 0.2540494 \\
3 & 0.0889539 & 0.2559092 & 0.2527305 & 0.2024449 \\
5 & 0.0978049 & 0.2761781 & 0.2481765 & 0.2174317 \\
7 & 0.1017948 & 0.2773066 & 0.2618466 & 0.2038673 \\
9 & 0.1111707 & 0.3006063 & 0.3134341 & 0.1352811 \\
11 & 0.1176309 & 0.2627596 & 0.1681487 & 0.1070523 \\
12 & 0.1221446 & $0.1579032 \star^{*}$ & $0.1154549 \star$ & \\
13 & 0.1196987 & & & $0.0814043 \star$ \\
15 & 0.0373830 & & & \\
17 & 0.0265482 & & & \\
19 & $0.0134478 \star$ & & & \\
\hline 1$)$
\end{tabular}

1) 50 대 $=f\left(50\right.$ 대 $\left._{t-i}\right)$

2) 50 대 $=f\left(50\right.$ 대 $_{t-19}, 20$ 대 $_{t-i}$ )

3) 50 대 $=f\left(50\right.$ 대 $_{t-19}, 30$ 대 $\left._{t-i}\right)$

4) 50 대 $=f\left(50\right.$ 대 $_{t-19}, 40$ 대 $\left._{t-i}\right)$

\section{5. 결론}

최근 인구고령화로 세대 간 일자리 경합문제가 제기되면서 세대 간 고용대체 현상의 발생 여부가 사회 적 관심사로 떠오르고 있으나 이에 대한 학문적 분석은 제대로 이루어지지 않고 있다. 고용동향을 나타 내는 중요 통계지표로 실업률이 주로 사용되어 왔으나 실제의 실업 상황을 과소측정하여 고용정책의 기 준을 대변하기에는 적절치 않다는 비판이 제기되어 왔다. 본 연구에서는 고용률의 월간자료를 사용하여 연령대별 고용 간 전반적 연관구도를 파악하기 위해 통계적으로 검정을 실시하였다. Granger 검정은 단기적으로는 30 대와 40 대 고용 간에만 연관성이 존재하는 것으로 나타나지만 시차가 길어지면 어떠한 연령대별 고용 간에도 통계적으로 유의한 인과관계가 존재하지 않는다. 이러한 성향의 검정결과는 분산 분해 및 충격반응분석에 의해서도 뒷받침되어 연령대별 고용 간 연계관계는 전반적으로 미약한 것으로 
나타났다. 또한 시차 선택의 임의성을 배제한 Hsiao 분석도 위의 결과를 뒷받침 하는 것으로 검정되어 일반적 예상과는 달리 연구기간 동안 장기적으로 일관되게 통계적으로 유의한 연령대별 고용 간 대체 및 보완관계는 성립되기 어려운 것으로 판명된다.

\section{References}

Akaike, H, (1969). Fitting autoregressive models for prediction, Annals of the Institute of Statistical Mathematics, 21, 243-247.

Card, D. and Lemieux, T. (2001). Can falling supply explain the rising return to college for younger men? A cohort-based analysis, The Quarterly Journal of Economics, 116, 705-746.

Chun, Y.-M. and Lee, S.-J. (2010). Classification and comparison of the type of graduates job mobility, The Korean Journal of Applied Statistics, 23, 235-247.

Diebold, F. X. and Nerlove, M. (1989). The dynamics of exchange rate volatility: A multivariate latent factor ARCH model, Journal of Applied Econometrics, 4, 1-21.

Hsiao, C. (1981). Autoregressive modelling and money income causality detection, Journal of Monetary Economics, 7, 85-106.

Hwang, S. K. (2010). Measurement of unemployment and extended unemployment indicators in Korea, Labor Economics Review, 33, 89-127.

Kang, S. H., Jun, J. S. and Lee, K. O. (1999). Improving method of unemployment statistics, Korea Labor Institute Research Report 99-10.

Kim, K. H. and Chang, D. K. (2005). Employment rate: A Concept and its empirical usefulress, The Bank of Korea, Economic Research Institute Economic Papers, 11, 106-135.

Kim, T. H. (2008). Estimating the structure of the short and the long run variations in the domestic youth unemployment, The Korean Journal of Applied Statistics, 21, 201-210.

Kwan, H. J. (2010). Job change by generations and employment policy tasks, Policy Research, 2010-10, Korea Employment Information Service.

Kwiatkowski, D., Phillips, P. C. B., Schmidt, P. and Shin, Y. (1992). Testing the null hypothesis of stationarity against the alternative of a unit root, Journal of Econometrics, 54, 158-178.

Lee, C. Y., Tae, W. Y., Kim, J. E. and Son, M. J. (2011). Economic aftermath of population ageing, Samsung Economic Research Institute Research Paper.

Lee, K. Y. (2005). Causal relationships between stock returns and inflation: The case of Korea, Kyong Je Hak Yon Gu, 54, 189-222.

$\mathrm{Ng}, \mathrm{S}$. and Perron, P. (1995). Unit root tests in ARMA models with data-dependent methods for the selection of the truncation lag, Journal of the American Statistical Association, 90, 268-281.

Schwert, G. W. (1987). Effects of model specification on tests for unit roots in macroeconomic data, Journal of Monetary Economics, 20, 73-105.

Sung, J. M. (2011). Analysis of changes in employment of 20-year-olds, Korea Labor Institute Monthly Labor Review, 76-96.

Thornton, D. L. and Batten, D. S. (1985). Lag-length selection and tests of Granger causality between money and income, Journal of Money, Credit and Banking, 17, 164-178.

Yoo, B. S. (2000). Structural vector autoregressive model, Journal of Economic Theory and Econometrics, 11, $87-111$. 